\title{
Microbiological study of cervical flora in preterm labour
}

\author{
Meenakshi Ruhil, Priti A. Hatkar* \\ Department of Obstetrics and Gynecology, Seth G. S. Medical College and K. E. M. Hospital, Mumbai, Maharashtra,
} India

Received: 16 January 2020

Accepted: 21 January 2020

*Correspondence:

Dr. Priti A. Hatkar,

E-mail: drpreetihatkar@rediffmail.com

Copyright: () the author(s), publisher and licensee Medip Academy. This is an open-access article distributed under the terms of the Creative Commons Attribution Non-Commercial License, which permits unrestricted non-commercial use, distribution, and reproduction in any medium, provided the original work is properly cited.

\begin{abstract}
Background: Preterm labour occurs due to various causative factors. Genital infections contribute significantly to the preterm labour. Ours is a prospective, observational study looking at the cervical microbiota involved in the preterm labour. The cervical flora contributing to the occurrence of preterm labour was studied. The results were analyzed based on the microbiological study of cervical swabs. The primary objectives of this study were to determine the association of cervical microbiota of pregnant women with spontaneous preterm delivery. To characterize the effect of cervical microbiota on birth gestation. The secondary objective of this study was to analyse the role of cervical microbiota and its relationship between social and behavioural factors.

Methods: It is a prospective, observational study, which includes 193 patients, studied over a period of one and a half year. It was conducted at our tertiary care centre after the approval by ethics committee, and the results were analysed. As this is a purely observational study, management decisions of treating obstetrician were not interfered with. No additional cost, intervention or injury was caused to the study subject.

Results: In our study, cervical swab culture shows growth in $2.07 \%$ which is statistically insignificant. Though, it was found that preterm labour is more common with leucocytosis, i.e. WBC $>11000 \mathrm{cmm}$, which is found to be statistically significant ( $\mathrm{p}$ value $=0.023$ ).

Conclusions: In our study, we found that there was no significant association of cervical flora with preterm labour, though we found an association with leucocytosis.
\end{abstract}

Keywords: Cervical swabs, Microbiological flora, Preterm labour

\section{INTRODUCTION}

Preterm labour is defined as the onset of labour prior to completion of 37 weeks of gestation in a pregnancy beyond the period of viability. ${ }^{1}$ Preterm labour is said to be established if there is presence of uterine contractions, at least 4 in 20 minutes or eight in 60 minutes with progressive change in cervical score in the form of effacement, $80 \%$ or more and cervical dilatation greater than $1 \mathrm{~cm} .^{2}$ Fetal viability may be defined as gestational age more than 20 or 28 weeks, depending on the facilities available and prevailing neonatal survival rate in that country. ${ }^{3}$ There are many maternal or fetal factors that have been associated with preterm labour, including maternal demographic characteristics, nutritional status, pregnancy history, present pregnancy characteristics, psychological characteristics, adverse behaviors, infection, uterine contractions and cervical length, and biological and genetic factors. Preterm rupture of membranes and genital infections are among the major causes of preterm labour. This study is being carried out to analyse the cervical microflora in women with preterm labour and the factors affecting the preterm labour. The detailed history and the routine examination of the patients admitted with complaints of preterm labour were noted. The patients with preterm labour were examined 
and the findings were recorded. Cervical swabs were collected during the first examination. The physical examination including the definitive signs of preterm labour, general condition, investigations such as all routine investigations, cervical swab collection, urine routine and urine culture sensitivity with reports were noted. A case record form was maintained for each patient and the data was compiled.

The primary objectives of this study were to determine the association of cervical microbiota of pregnant women with spontaneous preterm delivery. To characterize the effect of cervical microbiota on birth gestation. The secondary objective of this study was to analyse the role of cervical microbiota and its relationship between social and behavioural factors.

\section{METHODS}

The study design was a prospective observational study. It was conducted over a period of one and half years. The patients with preterm labour were examined and the findings were recorded. Cervical swabs were collected during the first examination. The physical examination including the definitive signs of preterm labour, general condition, investigations such as all routine investigations, cervical swab collection, urine routine and urine culture sensitivity with reports were noted. A case record form was maintained for each patient and the data was compiled.

\section{Sample size}

Sample size calculation was done by PASS sample size calculator.

Total sample size $=\mathrm{Z} 2 \times \mathrm{P} \times \mathrm{Q} \times \mathrm{N} / \mathrm{E}^{2}$

$\mathrm{P}=$ estimated prevalence

$\mathrm{E}=$ desired prevalence

$\mathrm{Z}=$ appropriate value from the normal distribution for the desired confidence

$\mathrm{N}=$ total population

$\mathrm{S}=1.96 \times 1.96 \times 0.5 \times 0.5 \times 210 \times 12 / 25=193$

Sample size $=193$.

\section{Inclusion criteria}

- $\quad$ Patients in advanced stage of labour with at least 3-4 contractions in 60 minutes, with progressive change in cervical effacement of 80 percent or more. And cervical dilatation more than $5 \mathrm{~cm}$ i.e., irreversible stage in preterm labour that cannot be conserved at that stage

- Singleton gestation

- Medical disorders are excluded however patients with upper respiratory tract infections, urinary tract infections or skin infections are included in the study.

\section{Exclusion criteria}

- Preeclampsia

- Multiple gestational pregnancies

- Women less than 18 years of age

- Immunocompromised

- Preterm premature rupture of membranes

- Polyhydramnios

- Intra uterine growth retardation.

\section{Methodology}

\section{Specimen collection}

Cervical swab was collected by the residents of the respective unit/treating physician on routine basis as follows-

- The cervix was visualized prior to collection

- Collection of a cervical sample was performed with the patient in the dorsolithotomy position

- A sterile sims speculum of appropriate size was inserted into the vagina without lubrication and without touching the walls of vagina

- Extra mucous was collected from cervix using a swab. A fine cervical swab was inserted in the cervical canal, rotated gently for 15-20 seconds and then removed

- The swab was transported immediately to the laboratory along with an appropriately filled requisition form.

\section{Microbiological processing}

\section{Gross appearance of specimen}

Gross appearance of the material collected on swab in terms of consistency and presence or absence of mucous, pus and blood was recorded.

\section{Microscopy}

Gram's stained smears were prepared and the results were recorded with specific reference to the presence or absence of epithelial cells, clue cells, bacteria and their morphology, pus cells. Amsel criteria were applied in the laboratory for the presumptive diagnosis of bacterial vaginosis. It was considered suggestive of bacterial vaginosis if three of the following tests are positive:

a. An adherent and homogenous vaginal discharge with fishy odour

b. Vaginal ph $>4.5$

c. Detection of clue cells

d. An amine odour after addition of $\mathrm{KOH}$ 


\section{Isolation of aerobic bacteria and fungi}

Cervical swab samples were plated on 5\% sheep blood agar (SBA) and MacConkey's Agar. The plates were incubated aerobically at $37{ }^{\circ} \mathrm{C}$ and read after 24 and 48 hours.

\section{Antimicrobial susceptibility testing}

All isolates were tested by the Kirby Bauer Disk Diffusion (KBDDM) method as per CLSI standards and the results recorded. The reports of the cervical swabs sent to the microbiology were traced.

\section{Statistical analysis}

All the parameters were studied and analysed on the basis of percentages. As this was a purely observational study, the parameters were analysed using descriptive statistics i.e., percentages were calculated and $\mathrm{p}$ value was obtained.

\section{RESULTS}

Following parameters were studied and results obtained:

\section{Cervical microflora}

In our study of total 193 subjects, cervical swab culture shows growth in $2.07 \%$ and no growth in remaining $97.93 \%$ of cases, which is statistically insignificant. The microfloral growth in the study constitutes E. Coli (1.04\%), Kleibsella (0.52\%) and Enterococcus $(1.04 \%)$ (Figure 1).

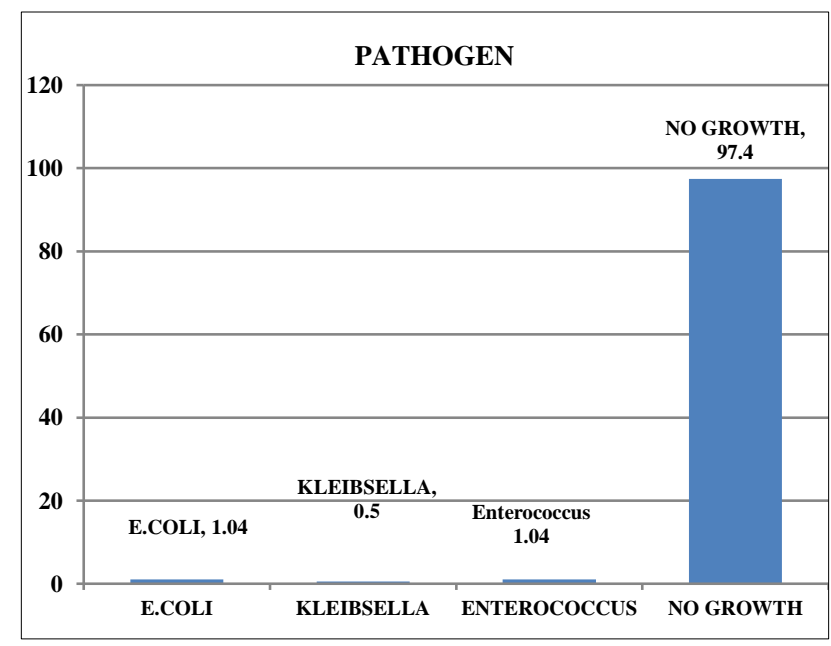

Figure 1: Cervical flora affecting preterm labour.

\section{Gestational age}

Preterm labour is more common in gestation age of 34-37 weeks of gestation (54.92\%), followed by 32-34.6 weeks (25.91\%) and least common amongst the 28-32 weeks of gestation (19.17\%) group Table 1.
Table 1: Distribution of subjects according to gestational age.

\begin{tabular}{|l|l|l|}
\hline Gestational weeks & Frequency & $\%$ \\
\hline 28 to 32 & 37 & 19.17 \\
\hline 32.1 to 34 & 50 & 25.91 \\
\hline 34.1 to 36.6 & 106 & 54.92 \\
\hline Total & $\mathbf{1 9 3}$ & $\mathbf{1 0 0}$ \\
\hline Mean & 33.48 & \\
\hline SD & 250 & \\
\hline Range & 32 to 38 & \\
\hline
\end{tabular}

\section{Psychosocial stress}

History of psychosocial stress factors during pregnancy such as personal and family problems does not alter the incidence of preterm labour and is statistically insignificant according to our study ( $p$ value 0.56 ) (Figure 2).

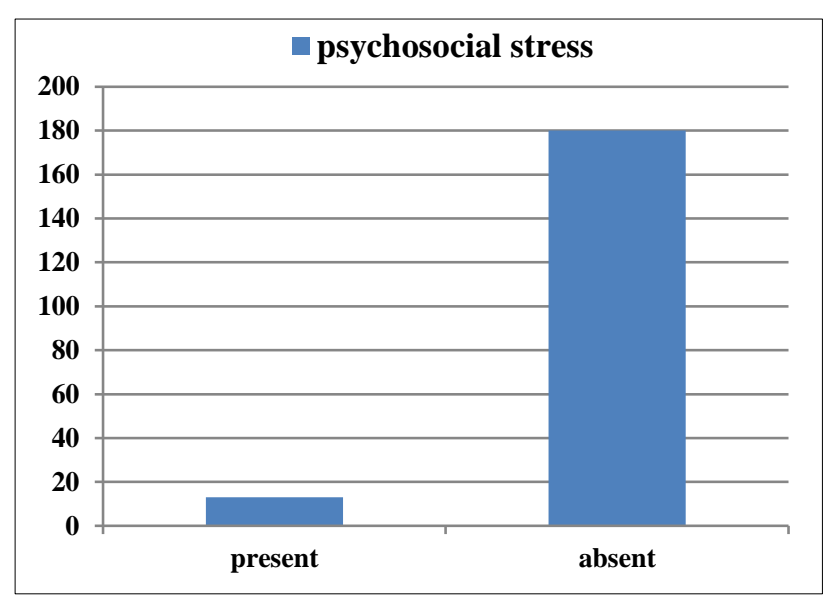

Figure 2: Distribution of subjects based on psychosocial stress.

\section{Use of vaginal hygiene products}

In our study, 2.59 percent of the participants had history of vaginal hygiene products (Figure 3) which is statistically insignificant ( $\mathrm{p}$ value 0.05 ).

\section{Addiction}

History of addiction in the form of alcoholism or tobacco addiction was studied. 2.59 percent of participants had tobacco addiction, which is statistically insignificant ( $p$ value $=0.70)($ Table 2$)$.

Table 2: Addiction and preterm labour.

\begin{tabular}{|lll|}
\hline Personal history & Frequency & $\%$ \\
\hline Smoking & 0 & 0 \\
\hline Tobacco & 5 & 2.59 \\
\hline Alcohol & 0 & 0 \\
\hline
\end{tabular}




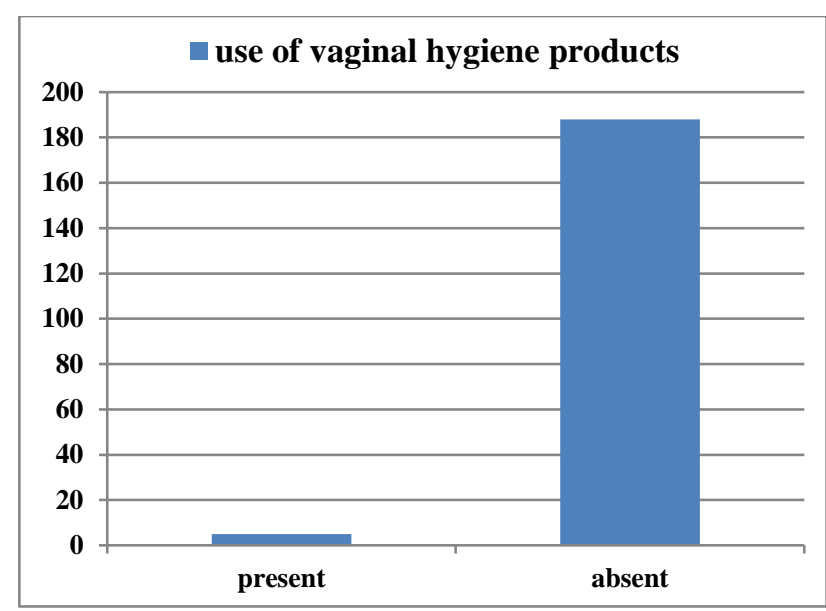

Figure 3: History of vaginal hygiene products and preterm labour.

\section{Parity and obstetric history}

It is observed that preterm labour is more common in multiparous $(53.9 \%)$ women as compared to primigravida in the study $(46.1 \%)$ (Figure 4). History of abortion is statistically insignificant (Table 3). History of MTP does not affect the incidence of preterm labour in this study and is statistically insignificant $(\mathrm{p}$ value $=0.74$ ) (Table 4). History of ectopic gestation does not affect the incidence of preterm labour and is statistically insignificant $(\mathrm{p}$ value $=0.925)($ Figure 5).

Table 3: Distribution of study subjects and abortion history.

\begin{tabular}{|lll|}
\hline Abortion & Frequency & $\%$ \\
\hline 0 & 169 & 87.56 \\
\hline 1 & 17 & 8.81 \\
\hline 2 & 6 & 3.11 \\
\hline 3 & 1 & 0.52 \\
\hline Total & $\mathbf{1 9 3}$ & $\mathbf{1 0 0 . 0 0}$ \\
\hline
\end{tabular}

Table 4: Distribution of study subjects based on history of MTP.

\begin{tabular}{|lll|}
\hline MTP & Frequency & Percentage \\
\hline Present & 5 & 2.59 \\
\hline Absent & 188 & 97.41 \\
\hline Total & $\mathbf{1 9 3}$ & $\mathbf{1 0 0 . 0 0}$ \\
\hline
\end{tabular}

Table 5: Various factors affecting preterm labor.

\begin{tabular}{|c|c|c|c|c|c|}
\hline Factors & Growth & & No growth & & p value \\
\hline & Nor/mean & $\% /$ SD & Nor/mean & $\% /$ SD & \\
\hline Gestational age & 33.25 & 2.99 & 33.40 & 2.43 & 0.9060 \\
\hline Gravida & 2.00 & 1.41 & 1.89 & 1.16 & 0.8503 \\
\hline \multicolumn{6}{|l|}{ Abortion } \\
\hline Zero & 3 & 75.0 & 165 & 87.77 & \multirow{4}{*}{$<0.001$} \\
\hline One & 0 & 0 & 17 & 9.04 & \\
\hline Two & 0 & 0 & 6 & 3.19 & \\
\hline \multirow[t]{2}{*}{ Three } & 1 & 25.0 & 0 & 0 & \\
\hline & 0.75 & 1.50 & 0.15 & 0.44 & 0.0145 \\
\hline \multicolumn{6}{|c|}{ Ectopic pregnancy } \\
\hline Zero & 4 & 100 & 181 & 96.28 & \multirow{3}{*}{0.9256} \\
\hline One & 0 & 0 & 6 & 3.19 & \\
\hline Two & 0 & 0 & 1 & 0.53 & \\
\hline \multicolumn{6}{|l|}{ MTP } \\
\hline Present & 0 & 0 & 5 & 2.66 & \multirow{2}{*}{0.7412} \\
\hline Absent & 4 & 100.00 & 183 & 97.34 & \\
\hline \multicolumn{6}{|c|}{ Social/psychological Stress } \\
\hline Yes & 0 & 0 & 13 & 6.88 & \multirow{2}{*}{0.5671} \\
\hline No & 4 & 100.00 & 176 & 93.12 & \\
\hline \multicolumn{6}{|l|}{ Tobacco } \\
\hline Yes & 0 & 0 & 5 & 2.65 & \multirow{2}{*}{0.7123} \\
\hline No & 4 & 100.00 & 184 & 97.35 & \\
\hline $\begin{array}{l}\text { Use of vaginal } \\
\text { hygiene products }\end{array}$ & 1 & 25.00 & 5 & 2.55 & 0.0600 \\
\hline No & 3 & 75.00 & 181 & 95.77 & \multirow{2}{*}{0.0237} \\
\hline WBC & 8200 & 1254.33 & 11034.81 & 3297.63 & \\
\hline
\end{tabular}




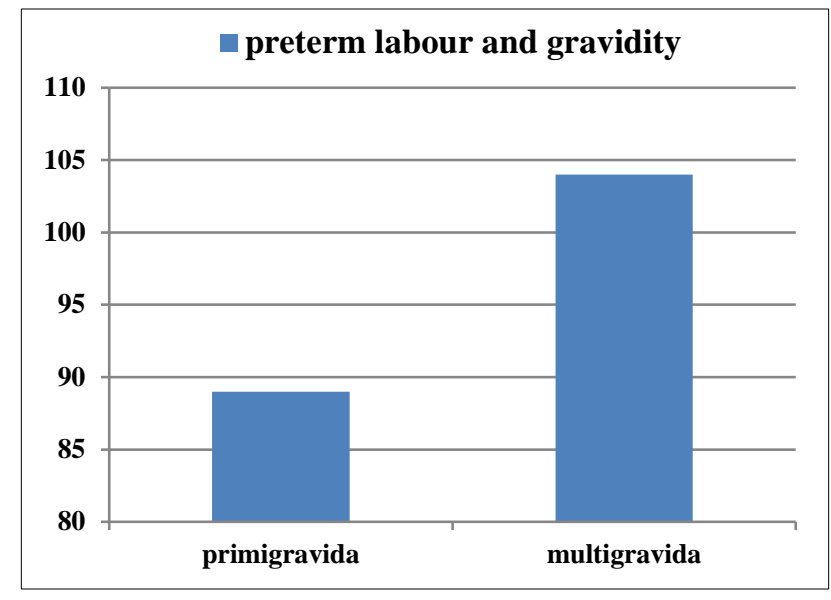

Figure 4: Preterm labour and gravidity.

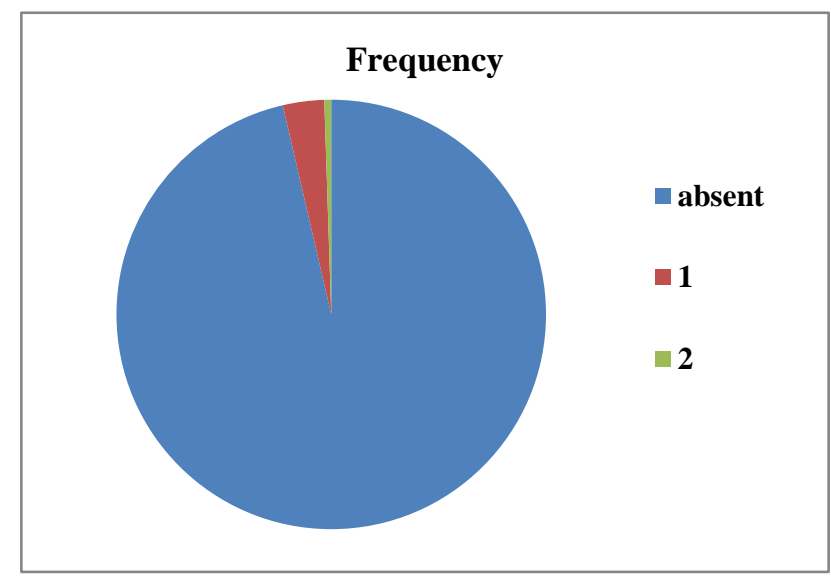

Figure 5: Distribution of study subjects based on history of ectopic in the past.

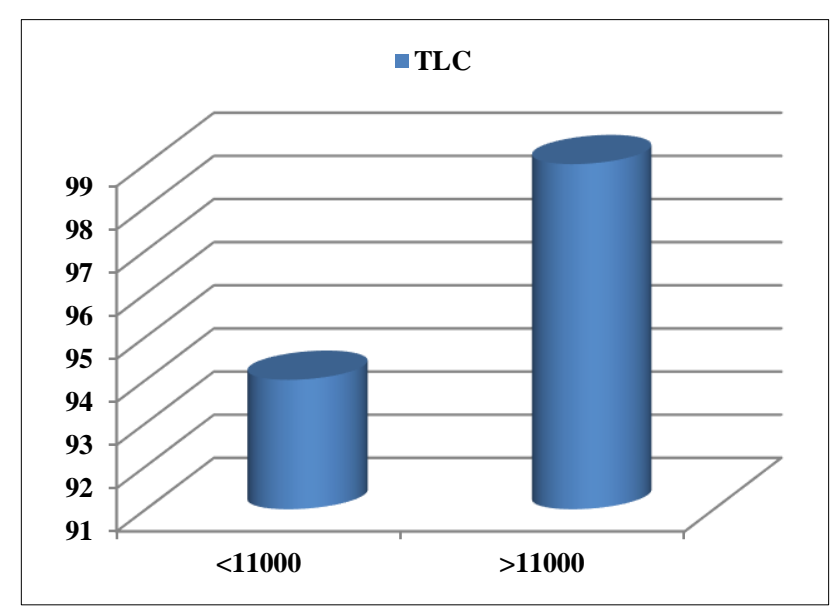

Figure 6: Leucocytosis and preterm labour.

\section{Leucocytosis}

In this study, preterm labour is more common with leucocytosis, i.e. WBC $>11000 \mathrm{cmm}$, which is found to be statistically significant $(\mathrm{p}$ value $=0.023)($ Figure 6$)$.

\section{DISCUSSION}

There is a rising trend of preterm labour over worldwide because of increased frequency of multiple births due to assisted reproductive techniques (ART), more working mothers, and increasing psychological stress and medically induced prematurity. Hence it is a time felt need to ascertain the causes and outcome of preterm labour. Detailed history taking, and general, systemic and obstetrical examinations were done paying special attention to presence or absence of conventional risk factors for preterm labour. All women with preterm labour were investigated for presence of infection by complete hemogram, and urine and vaginal swab culture. In our study, no significant relationship was found between the cervical flora and preterm labour, showing cervical flora growth in $2.07 \%$ of cases i.e. E. Coli, Enterococcus and Klebsiella. The results were in contrast with the study by Ovalle ET al who found that $63.5 \%$ of cervical swab cultures in preterm labour were positive, while the culture from amniotic cavity was positive in only $24 .{ }^{4}$ This may imply that cervical and intra-amniotic cavity colonization and histological inflammatory responses need time to incubate from initial bacterial invasion to histological and clinical manifestation. No significant relationship was found between evidence of cervical swab culture and clinical findings of chorioamnionitis in preterm labour with intact membranes. However, because of some limitations in this study, the role of cervical swab culture in preterm labour remains inconclusive.

A prospective study was conducted in obstetrics/gynecology departments of Health Center and the University Clinical Center Tuzla, and General Hospital Tešanj (Bosnia and Herzegovina, B and $\mathrm{H}$ ) between October 2013 and May 2014. An examined group included 50 healthy pregnant women with singleton pregnancy of the gestation age between the $28^{\text {th }}$ and $37^{\text {th }}$ week, with cervical changes that are related to imminent preterm labor. Changes were detected by ultrasound biometry of cervix and modified Bishop Score. A control group included 30 healthy pregnant women with singleton pregnancy of the gestation age between the $28^{\text {th }}$ and $37^{\text {th }}$ week of pregnancy without signs of imminent preterm labor. Cervical mucus was microbiologically analyzed for identification of pathogens. The infection in cervical canal was proven in $35(70 \%)$ examinees and four $(13 \%)$ patients from the control group $(p=0.015)$. In seven $(20 \%)$ cases each Ureaplasma and Mycoplasma were detected followed by $E$. Coli in five $(14 \%)$ cases $(\mathrm{p}=0.001) .{ }^{5}$ In our study, there was no statistically significant association between cervical microbiota and the birth gestation ( $\mathrm{p}$ value$0.906)$. Of all the preterm labour cases, maximum cases (54.92\%) occurred at 34-36 weeks gestation, which was statistically insignificant. According to a study conducted at 18 maternity hospitals. Cases were selected based on criteria determined by the study's technical committee, which consisted of representatives from the United 
Nations International Children's Emergency Fund (UNICEF), the World Health Organization (WHO), and the Jordanian health sectors, preterm delivery incidence was $85 \%$ were in $32-36$ gestational weeks. ${ }^{6}$

In this study, psychosocial stress contributes $6.74 \%$ to the preterm labour which is statistically insignificant. In contrast, some studies show that women experiencing high levels of psychosocial stress during pregnancy are at significantly increased risk of preterm delivery, even after accounting for the effects of other established sociodemographic, biophysical, biomedical, and behavioral risk factors. ${ }^{7}$ In this study, addiction i.e. contributed only $2.59 \%$ of the preterm births which is statistically insignificant.

Pratinidhi et al, had examined the relationship of SLT use with all three outcomes, low birth weight, preterm birth and still birth. ${ }^{8}$ The study by Pratinidhi et al was a cohort study enrolling about 700 pregnant women recruited from primary health centres in Pune. They reported a significantly increased risk of low birth weight and stillbirth but no significant association of tobacco addiction with preterm birth.

A study by Chang et al, presents recent review showing potential reduction $(0.01 \%)$ in preterm labour with smoking cessation. ${ }^{9}$ Based on our research, smoking cessation early in pregnancy has an additional impact on reducing preterm births. Some studies prove that there is no significant relationship between alcohol consumption during pregnancy and preterm labour. ${ }^{10}$ In this study, 4.66 percentages of the participants had history of vaginal hygiene products which is statistically insignificant. The results are in contrast to the study by Bruce et al who reported a reduction in preterm birth risk if there is history of douching in the six months prior to pregnancy. ${ }^{11}$

In the present study, preterm labour is more common in multigravida $(53.9 \%)$ than primigravida $(46.1 \%)$ which is statistically insignificant.

These findings are similar to a case-control study which was conducted in the maternity ward of Imam Sajjad Hospital, the obstetrics and gynecology center of Yasuj, in 2010. Among the 5400 live birth infants in Yasuj in 2010, 130 infants were premature $(2.4 \%)$. The preterm labor risk in women with two or more pregnancies was 5.5 times more than women with less than two pregnancies. $^{12}$ In this study history of MTP associated with only $2.59 \%$ of preterm labour, which is statistically insignificant. Similar results from studies by Chen et al, who compared pregnancy outcomes in women with one previous mifepristone induced abortion (IA) with pregnancy outcomes in women with no previous IA. ${ }^{13}$ The study demonstrated that there is no association between previous medical induced abortion and preterm labour. In this study, leucocytosis was found to be associated with $51.30 \%$ of the preterm labour cases, which was statistically significant. The study approved by the Human Research Committee at the University of Texas Medical Branch (UTMB) in Nashville Tennessee shows that elevated levels in the peripheral WBC's of $71 \%$ of tested PTL patients as compared to $6 \%$ of pregnant control patients. ${ }^{14}$

\section{CONCLUSION}

Our study was prospective cohort study. It was conducted in tertiary care centre. Total 193 participants were enrolled in the study. In our study, of all the preterm labour cases, maximum cases $(54.92 \%)$ occurred at 34-36 weeks gestation. Preterm labour was found to be more common in multigravida $(53.9 \%)$ than primigravida $(46.1 \%)$. In our study, no significant relationship is found between the cervical flora and preterm labour. Psychosocial stress and personal habits contribute minimally to the preterm labour according to the study. Leucocytosis is associated with increased rates of preterm labour according to our study. Hence further large scale studies need to be conducted which will determine the role of cervical flora in preterm labour.

\section{Funding: No funding sources}

Conflict of interest: None declared

Ethical approval: The study was approved by the Institutional Ethics Committee

\section{REFERENCES}

1. Chandraharan E, Arulkumaran S. Recent advances in management of preterm labour. J Obstet Gynecol India. 2005;5(52):118-24.

2. Arias F, Daftary SN, Bhide AG. Textbook of practical guide to high risk pregnancy and delivery. Asouth Asian perspective ( $3^{\text {rd }}$ edition). 2008;194261.

3. Mokuolu OA, Suleiman B, Adesiyun O, Adeniyi A. Prevalence and determinants of pre-term deliveries in the University of Ilorin Teaching Hospital, Ilorin Nigeria. Pediatr Rep. 2010;2:e3.

4. Ovalle A, Martinez MA, Gómez R, Sáez J, Menares I, Aspillaga C. Premature labor with intact membranes: microbiology of the amniotic fluid and lower genital tract and its relation with maternal and neonatal outcome. Rev Med Chil. 2000;128:985-95.

5. Chalermchockchareonkit A, Phoethong S, Ruangvutilert P, Thamkhantho M. Prevalence of positive culture of genitourinary tract microorganisms in pregnant women with presumptive preterm labor. J Med Assoc Thai. 2013;96:1111-8.

6. March of Dimes; PMNCH; Save the Children; WHO. Born Too Soon: The Global Action Report on Preterm Birth. Eds CP Howson, MV Kinney, JE Lawn. Geneva. 2012. Available at: https://www.who.int/pmnch/media/news/2012/20120 4_borntoosoon-report.pdf. Accessed on $10^{\text {th }}$ January 2019. 
7. Dunkel Schetter C. Psychological science on pregnancy: stress processes, biopsychosocial models, and emerging research issues. Annu Rev Psychol. 2011;62:531-58.

8. Pratinidhi A, Gandham S, Shrotri A, Patil A, Pardeshi S. Use of "mishri" a smokeless form of tobacco during pregnancy and its perinatal outcome. Indian J Commun Med. 2010;35:14-8.

9. Chang HH, Larson J, Blencowe H, Spong CY, Howson CP, Cairns-Smith S, et al. Preventing preterm births: analysis of trends and potential reductions with interventions in 39 countries with very high human development index. Lancet. 2013;381:223-34.

10. McCarthy FP, O'Keeffe LM, Khashan AS, North RA, Poston L, McCowan LM, et al. Association between maternal alcohol consumption in early pregnancy and pregnancy outcomes. Obstet Gynecol. 2013;122:830-7.

11. Bruce C, Kendrick J, Kieke B, Jagielski S, Joshi R, Tolsma D. Is vaginal douching associated with preterm delivery? Epidemiol. 2002;13:328-33.
12. Covarrubias LO, Aguirre GE, Chapuz JR, May AI, Velázquez JD, Eguiluz ME. Maternal factors associated to prematurity. Ginecol Obstet Mex. 2008;76(9):526-36.

13. Chen A, Yuan W, Meirik O, Wang X, Wu SZ, Zhou $\mathrm{L}$, et al. Mifepristone-induced early abortion and outcome of subsequent wanted pregnancy. Am J Epidemiol. 2018;160(8):110-7.

14. Nowicki S, Izban MG, Pawelczyk E, Agboto VK, Pratap S, Olson G, et al. Preterm labor: CD55 in maternal blood leukocytes. Am J Reprod Immunol. 2009;61(5):360-7.

Cite this article as: Ruhil M, Hatkar PA.

Microbiological study of cervical flora in preterm labour. Int J Reprod Contracept Obstet Gynecol 2020;9:945-51. 